\title{
Differential somatic cell count in milk before, during, and after lipopolysaccharide- and lipoteichoic-acid-induced mastitis in dairy cows
}

\author{
Samantha K. Wall, ${ }^{* 1,2}$ Olga Wellnitz, ${ }^{*}$ Rupert M. Bruckmaier, ${ }^{*}$ and Daniel Schwarz $\dagger^{1,3}$ \\ *Veterinary Physiology, Vetsuisse Faculty, University of Bern, CH-3001 Bern, Switzerland \\ †FOSS Analytical A/S, Foss Allé 1, 3400 Hillerød, Denmark
}

\begin{abstract}
Intramammary infections induce the initiation of the inflammatory response, resulting in an increase in somatic cell count (SCC) in milk. The SCC includes several different types of cells but does not differentiate between them. On the contrary, the new differential somatic cell count (DSCC) parameter allows for the differentiation between 2 groups of cells: polymorphonuclear neutrophils (PMN) and lymphocytes versus macrophages. Therefore, the aim of this paper was to describe the changes of both DSCC and SCC during mastitis induced by cell wall components from typical mastitis-causing pathogens [lipopolysaccharide (LPS), Escherichia coli; lipoteichoic acid (LTA), Staphylococcus aureus] known to trigger different severities of mastitis. In addition, the effect the glucocorticoid prednisolone (PRED), which is known to attenuate the immune response in the mammary gland, was investigated. Twenty dairy cows were equally divided into 5 groups and treated with LPS, LTA, LPS+PRED, LTA+PRED, or a saline control. Milk samples were taken at the following time points: baseline $(\mathrm{d}-3,-2$, and -1$)$, right before treatment $(\mathrm{d} 0), 5 \mathrm{~h}$ after treatment (d 0.2 ), early cure phase (d 1 and 2), and late cure phase (d 3, 4, 5, 6, 7, and 14) and analyzed for DSCC and SCC. Mean DSCC values increased significantly from $<60 \%$ at baseline and right before treatment to $>81 \% 5 \mathrm{~h}$ after treatment and the early cure phase in all groups, except for the groups control and LTA+PRED. This increase clearly reflects a shift in cell populations to predominantly PMN. The SCC increased significantly following the stimulation, too, as expected. Interestingly, we observed cases where SCC increased moderately only whereas DSCC showed an evident increase,
\end{abstract}

\footnotetext{
Received November 18, 2017.

Accepted February 14, 2018.

${ }^{1}$ These authors contributed equally.

${ }^{2}$ Current address: Elanco Animal Health, 2500 Innovation Way, Greenfield, IN 46140.

${ }^{3}$ Corresponding author: das@foss.dk
}

meaning that the shift in cell populations occurred even at low SCC levels. The PRED clearly lowered the cell migration in group LTA+PRED. This is the first ever study investigating DSCC during induced mastitis under controlled conditions. The combination of DSCC and SCC could be employed for the earlier detection of mastitis by revealing the shift in cell population independent from the SCC level. Furthermore, combining DSCC and SCC information could help to determine the stage of mastitis because we observed high DSCC and SCC results in the early stage of mastitis but evidently lower DSCC and high SCC in the cure phase. Hence, our results offer the first fundamental insights on how mastitis monitoring could be improved in the frame of dairy herd improvement programs.

Key words: mastitis, udder health, differential somatic cell count, Escherichia coli, Staphylococcus aureus

\section{INTRODUCTION}

Mastitis is mostly caused by bacterial pathogens invading the mammary gland. Typical pathogens, namely Escherichia coli, a gram-negative bacterium usually associated with acute, clinical mastitis, and Staphylococcus aureus, a gram-positive bacterium often associated with chronic mastitis, can cause differential activation of the immune system (Bruckmaier and Wellnitz, 2017).

Bacteria have specific cell wall components embedded in their cell wall, namely LPS on E. coli and lipoteichoic acid (LTA) on $S$. aureus. Intramammary injection of these bacterial cell wall components can be used to induce inflammation equal to that occurring during mastitis (Wellnitz et al., 2013). Furthermore, glucocorticoids have been known to affect the bovine immune system (Roth and Kaeberle, 1981, 1982), and specifically, the glucocorticoid prednisolone (PRED) can influence the recruitment of neutrophils given that it has been known to affect the recruitment of immune cells to the site of infection (Schwiebert et al., 1996; Sipka et al., 2013).

Somatic cell counts in milk provide an indication of the inflammatory response in the mammary gland and 
hence a proxy for measuring IMI. The optimal cut-off point to distinguish between infected and uninfected quarters at the cow level has been established at 200,000 cells/mL (IDF, 2013). Besides the well-established SCC, cell differentiation measurements provide more detailed insights on the actual inflammatory status of mammary glands and thus udder health status (e.g., Pilla et al., 2013). Whereas SCC represents the total number of cells, cell differentiation refers to the proportions of individual cell populations such as lymphocytes, macrophages, and PMN that play an important role in inflammatory responses within the mammary gland (Paape et al., 1979; Sordillo and Nickerson, 1988; Sordillo et al., 1997).

A new parameter for cell differentiation in milk, the differential somatic cell count (DSCC) parameter, has recently been described (Damm et al., 2017). Briefly, DSCC indicates the percentage of PMN combined with lymphocytes. Proportions of macrophages can be calculated by 100 - DSCC. Percentages of DSCC were described to vary in a broad range in the low SCC range but increase as SCC increases (Damm et al., 2017).

To our knowledge, this is the first study to examine DSCC during the occurrence of mastitis under controlled conditions. Therefore, the primary objective of this study was to describe the changes of the new parameter, DSCC, as well as SCC, before, during, and after mastitis induced by LPS from E. coli, or LTA from $S$. aureus, with or without administration of the glucocorticoid PRED. Furthermore, the interrelation of DSCC and SCC in different types of milk samples (i.e., quarter foremilk, quarter composite, and cow composite) was investigated. The aim of this study was to contribute to the basic understanding of the practical application of the new DSCC parameter (e.g., determination of the stage of mastitis).

\section{MATERIALS AND METHODS}

\section{Animals}

All animal trials were approved and permitted by the Committee of Animal Experiments, Canton of Fribourg, Switzerland, and all experimental procedures followed the Swiss law of animal protection. Twenty dairy cows (Holstein Friesian) in mid-lactation [DIM (on challenge day) $=195.8 \pm 18.1$; mean $\pm \mathrm{SD}]$ were selected. Parities of experimental cows ranged from 1 to 6 and cows were producing $>15 \mathrm{~kg}$ of milk/d (mean milk yield $=$ $20.5 \pm 0.8 \mathrm{~kg}$ ). All cows had a SCC $<150,000$ cells $/ \mathrm{mL}$ in all 4 quarters during the $3 \mathrm{~d}$ before the experiment and showed no signs of clinical mastitis. Cows were examined by a veterinarian, and overall health status was determined by a blood glutaraldehyde coagula- tion test (Sandholm, 1976; Tøllbøll and Jørgensen, 2003) before the experiment. The glutaraldehyde test was considered negative if no clotting occurred within $10 \mathrm{~min}$. Cows were housed at the Agroscope research station (Posieux, Canton of Fribourg, Switzerland) in straw and sawdust bedded tiestalls throughout the experiment. Cows were fed roughage ad libitum and $1 \mathrm{~kg}$ of energy concentrate daily. Water was also available ad libitum. Cows were machine milked regularly, twice daily at 0530 and $1600 \mathrm{~h}$.

\section{Experimental Procedures and Treatments}

On the day of the experiment, cows were randomly allocated to 5 treatment groups (group A, control, $\mathrm{n}=$ 4; group B, LPS, $\mathrm{n}=4$; group C, LPS+PRED, $\mathrm{n}=4$; group D, LTA, $\mathrm{n}=4$; and group E, LTA+PRED, $\mathrm{n}=$ 4 ), and mammary glands were challenged according to Figure 1 and as described elsewhere (Wall et al., 2016). Briefly, immediately following morning milking, 2 quarters from each cow were injected via the teat canal and each quarter received a co-injection of 2 treatments from separate sterile syringes. The injections were performed by sterilizing each teat with gauze soaked in $70 \%$ ethanol and inserting a sterilized teat cannula. A 15-s massage in the cisternal direction was performed immediately after injection.

Treatments were prepared as follows: $0.2 \mu \mathrm{g}$ of LPS (from E. coli serotype O26:B6, Sigma-Aldrich, St. Louis, MO) diluted in $10 \mathrm{~mL} \mathrm{0.9 \%} \mathrm{sterile} \mathrm{saline;} 20 \mu \mathrm{g}$ of LTA (from S. aureus, Sigma-Aldrich) diluted in 10 $\mathrm{mL}$ of $0.9 \%$ sterile saline; $30 \mathrm{mg}$ of PRED (prednisolone sodium phosphate, Santa Cruz Biotechnology, Dallas, TX) diluted in $10 \mathrm{~mL}$ of double distilled water; the control treatment was $10 \mathrm{~mL}$ of $0.9 \%$ sterile saline. Time of injection was designated as time/d 0. Each cow had 1 treatment and 1 control quarter (Figure 1).

\section{Sampling Procedures}

Quarter Foremilk Samples. Before milking, teats and teat ends were cleaned using a 1-way cloth and the first 2 squirts of milk were discarded. Volumes of $10 \mathrm{~mL}$ of milk were collected per udder quarter. All samples were preserved with Broad Spectrum Micro tabs (Advanced Instruments Inc., Norwood, MA) to a final concentration of bronopol and natamycin of 0.27 and $0.01 \mathrm{mg} / \mathrm{mL}$ of milk, respectively. Only treatment and control quarters were sampled from each cow.

Sampling Schedule. Quarter foremilk samples were taken from all 4 quarters on $\mathrm{d}-3,-2$, and -1 at the morning milking to establish a baseline. On the day of the challenge, samples were collected at 0 and $5 \mathrm{~h}$ postchallenge (i.e., d 0 and 0.2 ). Whereas samples were 
1.

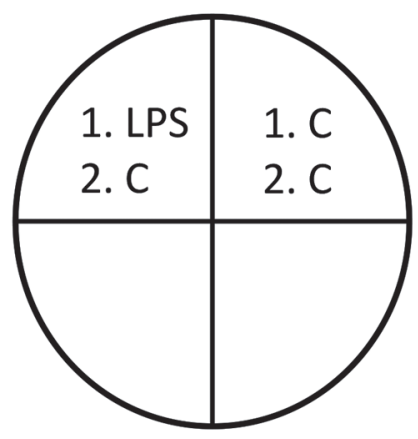

4.

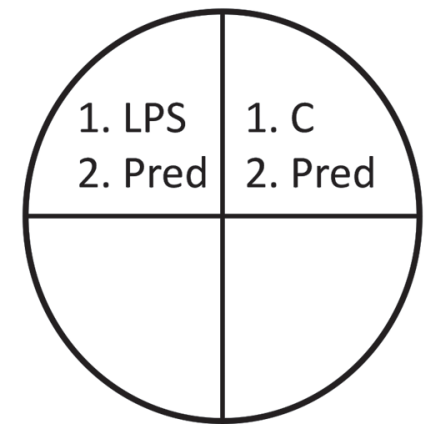

2.

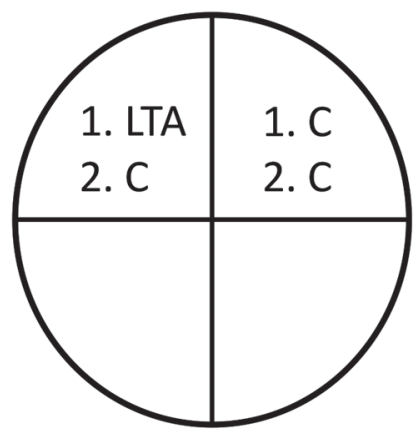

5.

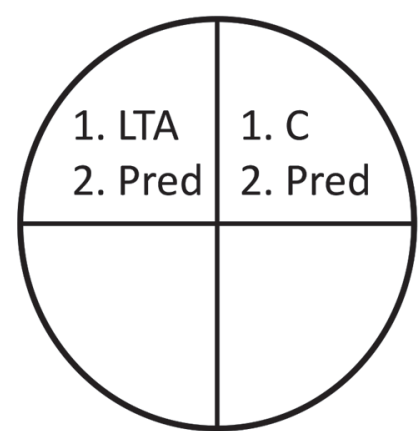

3.

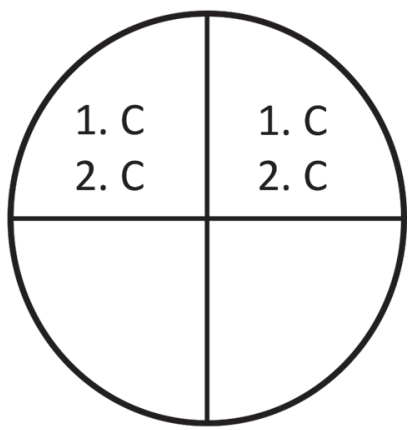

Figure 1. Cows received a co-injection (two 10-mL injections) at time/d 0, denoted by 1 and 2 within each quarter on the figure.

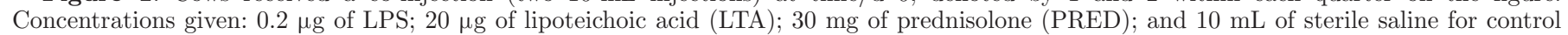
(C). Treatment quarters were randomly assigned for each cow to ensure no sampling bias was present.

collected both at morning and evening milkings on $\mathrm{d} 1$ and 2 , only morning milkings were used for sampling on d $3,4,5,6,7$, and 14 .

For statistical purposes, the following time points were defined: (1) baseline (i.e., $\mathrm{d}-3,-2$, and -1 ); (2) right before treatment (i.e., d 0); (3) $5 \mathrm{~h}$ after treatment (i.e., d 0.2); (4) early cure phase (i.e., d 1 and 2); (5) late cure phase (i.e., d 3, 4, 5, 6, 7, and 14).

Samples for Bacteriology. Sterile quarter foremilk samples with a volume of $10 \mathrm{~mL}$ were collected from each udder quarter on $\mathrm{d}-2,1$, and 14 in accordance with NMC (2004) standards. These samples were collected after the above-described quarter foremilk samples.

Additional Milk Samples. In total, 6 randomly selected animals were used for collection of additional samples at $\mathrm{d}-2$ and 5 relative to treatment. Besides quarter foremilk samples, quarter composite samples were collected by milking each udder quarter separately into individual containers using a quarter milking machine. Quarter composite samples with volumes of 10 $\mathrm{mL}$ each were collected after proper stirring of the individual containers for $1 \mathrm{~min}$. Contents of all 4 containers were afterward mixed together, stirred for $1 \mathrm{~min}$, and 10-mL cow composite samples was taken. These ad- ditional milk samples were taken to study the interrelation of DSCC and SCC results in quarter foremilk and quarter composite as well as quarter composite and cow composite samples.

Mammary Gland Biopsies. Mammary gland biopsies were performed according to Zarrin et al. (2014) for purposes of another study (Wall et al., 2016). In short, biopsies were obtained from 2 quarters, one treated and one control, at $4 \mathrm{~h}$ after challenge. Mammary gland tissue ( $\sim 30$ to $60 \mathrm{mg}$ ) was obtained by ultrasound-guided biopsy under local anesthesia $(10 \mathrm{~mL}$ of $2 \%$ lidocaine, Streuli Pharma AG, Uznach, Switzerland) using a biopsy needle (12 gauge $\times 10 \mathrm{~cm}$; Bard Magnum Core Tissue Biopsy Needle; Bard GmbH, Türkenfeld, Germany). Biopsied quarters were not used for quarter milk sampling.

\section{Laboratory Analyses}

DSCC and SCC. Determination of DSCC and SCC was performed according to Damm et al. (2017). Briefly, milk samples were stained with FOSS DC Reagent (ratio 1:3.2), incubated at $40^{\circ} \mathrm{C}$ for $1 \mathrm{~min}$, vortexed for $5 \mathrm{~s}$, and immediately analyzed on an Attune (Thermo Fisher Scientific, Waltham, MA) flow cytom- 
eter. FlowJo (FlowJo LLC, Ashland, OR) software was used to determine DSCC and SCC.

Bacteriological Examination. Analysis of bacteriology was performed according to NMC (2004) standards. In brief, from each thawed sample, $10 \mu \mathrm{L}$ of milk was streaked onto a quadrant of $7 \%$ bovine blood agar plate containing $0.05 \%$ esculin (Merck KGaA, Darmstadt, Germany) and incubated aerobically for 24 to $48 \mathrm{~h}$ at $37^{\circ} \mathrm{C}$. Samples were considered to be culture positive if one or more colonies were observed $(\geq 100$ $\mathrm{cfu} / \mathrm{mL}$ ). Identification of bacteria was done by Gram staining, inspection of the colony morphology, and biochemical testing. Catalase tests were performed to differentiate gram-positive cocci as catalase positive or negative. Samples yielding 3 or more different bacterial species were considered to be contaminated.

\section{Statistical Analysis}

All results are presented as means \pm standard error of the mean. Statistical analysis of SCC (at a logarithmic scale, $\log _{10}$ ) and DSCC was performed using ANOVA from the mixed procedure of SAS (version 9.4, SAS Institute Inc., Cary, NC) with Tukey-Kramer adjustment. The model included time, treatment, and the interaction between both (time $\times$ treatment) as fixed effects and cow as the repeated subject. The values for the 2 control quarters in control cow and control cow PRED groups were averaged for comparison with the other groups in the trial. Control quarters from LPS and LTA challenged cows were all treated as the control quarters as there were no statistical differences. For DSCC, samples with $<50,000$ cells $/ \mathrm{mL}$ were set to $45 \%$ due to quarters below this value being out of the performance range and thus not reliable (Damm et al., 2017). Values were considered significant when $P$ $<0.05$.

\section{RESULTS}

In total, 20 cows were challenged with 5 different treatments (groups A-E: A = control, group B = LPS, group $\mathrm{C}=\mathrm{LPS}+\mathrm{PRED}$, group $\mathrm{D}=\mathrm{LTA}$, and group $\mathrm{E}=\mathrm{LTA}+\mathrm{PRED})$ and the changes of the parameters DSCC and SCC were investigated both within treatment groups (i.e., over the course of treatment) and between treatment groups. The period from $\mathrm{d}-3$ to 14 relative to treatment was investigated. Besides the control group, one udder quarter of each cow was used as a control quarter. The DSCC parameter indicates the percentage of PMN combined with lymphocytes (Damm et al., 2017). Proportions of macrophages can be calculated by 100 - DSCC.

The variance analysis revealed that only treatment had a significant $(P<0.001)$ influence on both DSCC and SCC at d 0.2 as well as 1 and 2, respectively (Table 1). Neither DIM nor parity or milk weight influenced DSCC or SCC. The only exception was a significant $(P$ $<0.05$ ) influence of DIM and milk weight on SCC at d -3 to -1 .

\section{Changes of DSCC and SCC Within Treatment Groups}

To investigate the changes of both DSCC and SCC values before, during, and after the challenge $(\mathrm{d}-3$ to 14), the 2 parameters were analyzed individually for each treatment group (A-E; Figure 2).

$S C \boldsymbol{C}$. Treated quarters of cows in group A revealed mean logarithmic SCC values between 4.14 and 4.70

Table 1. Results of variance analysis ${ }^{1}$ for SCC and differential somatic cell count (DSCC), depending on time

\begin{tabular}{llllll}
\hline Item & $\begin{array}{l}\text { Time } \\
\text { point }^{2}\end{array}$ & DIM & Parity & Milk weight & Treatment \\
\hline SCC & & $*$ & & & \\
& 1 & NS & NS & NS & NS \\
& 2 & NS & NS & NS & $* * *$ \\
& 3 & NS & NS & NS & NS \\
& 4 & NS & NS & NS & NS \\
DSCC & 5 & NS & NS & NS & NS \\
& 1 & NS & NS & NS & $* * *$ \\
& 2 & NS & NS & NS & NS \\
& 3 & NS & NS & NS & NS \\
& 4 & NS & NS & &
\end{tabular}

${ }^{1}$ Analyzed factors were DIM $(\leq 100,101-200,201-300$, and $>300)$, parity $(1,2,3$, and 4$)$, milk weight $(<17.5$, $17.5-20,20-22.5,>22.5)$, and treatment (A-E).

${ }^{2}$ Time point: (1) baseline (i.e., $\mathrm{d}-3,-2$, and -1 ); (2) right before treatment (i.e., d 0); (3) $5 \mathrm{~h}$ after treatment (i.e., d 0.2); (4) early cure phase (i.e., d 1 and 2); and (5) late cure phase (i.e., d 3, 4, 5, 6, 7, and 14).

*** $P<0.001 ;{ }^{*} P<0.05$; NS: $P>0.05$. 
WALL ET AL.

山i

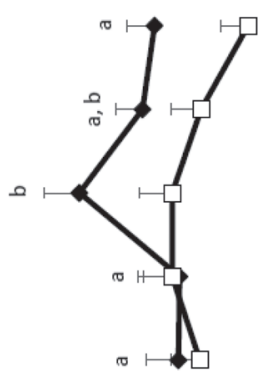

$\dot{\theta}$

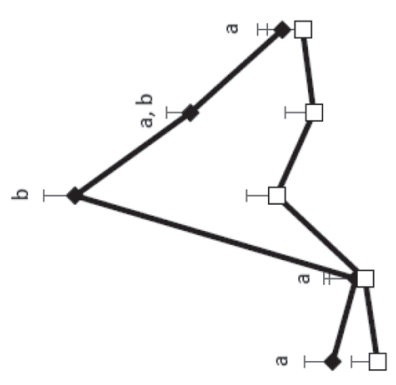

ن

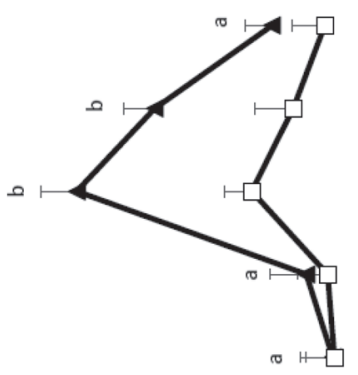

$\infty$
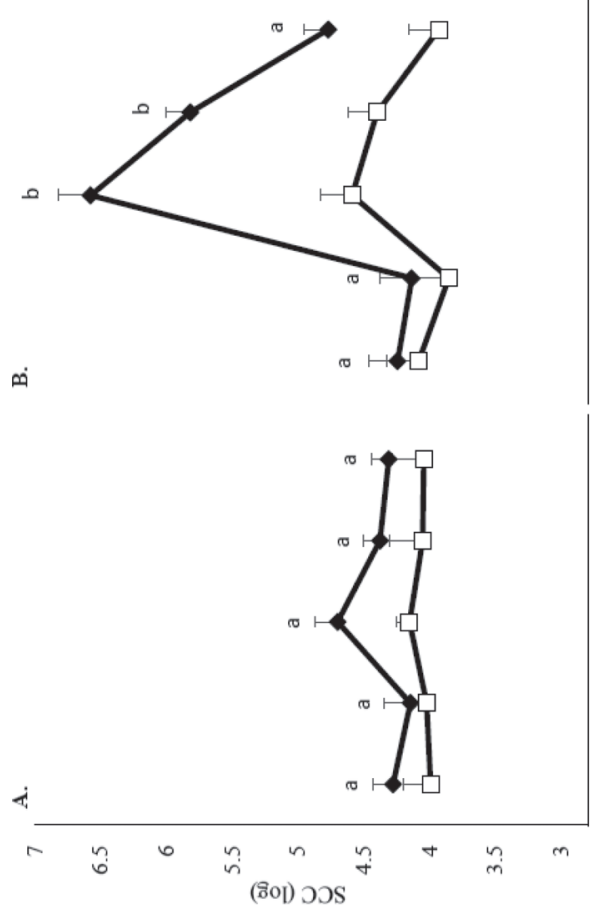

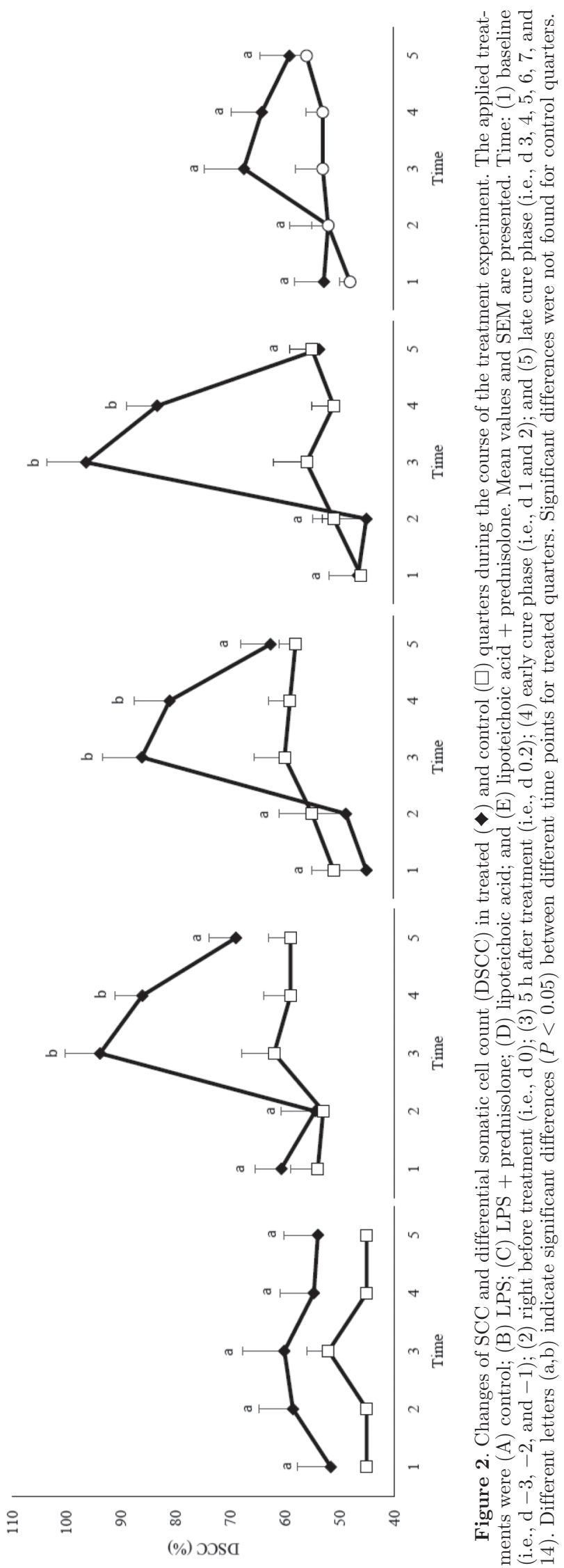


Table 2. Comparison of logarithmic SCC values (mean \pm SEM) measured in treated quarters between treatment groups (A-E)

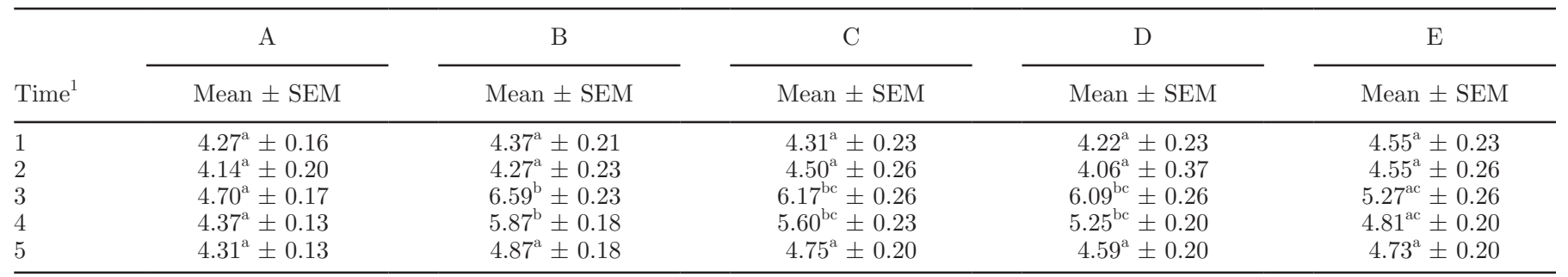

${ }^{\mathrm{a}-\mathrm{c}}$ Different superscripts within a row indicate significant differences at $P<0.05$.

${ }^{1}$ Time: (1) baseline (i.e., $\mathrm{d}-3,-2$, and -1 ); (2) right before treatment (i.e., d 0); (3) 5 h after treatment (i.e., d 0.2); (4) early cure phase (i.e., d 1 and 2); and (5) late cure phase (i.e., d 3, 4, 5, 6, 7, and 14).

and did not indicate any significant differences (Figure 2).

Somatic cell count results for treated quarters of cows in groups B to $\mathrm{E}$ varied in a wide range (4.06 to 6.59; Figure 2). In groups B and C, mean values from 4.27 to 6.59 and 4.31 to 6.09 , respectively, were found, where mean $\log$ SCC was significantly $(P<0.05)$ higher at d 0.2 as well as d 1 and 2 compared with d -3 to -1 , 0 , and 3 to 14 . Group D revealed SCC values between 4.06 and 6.09 and a significant $(P<0.05)$ increase in $\mathrm{SCC}$ from d 0 to 0.2 was observed. In group E, mean $\log$ SCC values varied in a narrower range from 4.55 to 5.29 , yet the increase from d 0 to 0.2 was significant $(P$ $<0.05)$.

Mean logarithmic SCC values determined in control quarters across groups A to E were generally low (3.99 to 4.90) and did not show any significant differences (Figure 2).

DSCC. Mean DSCC values in milk of treated quarters in group A ranged narrowly from 52 to $60 \%$, whereas those in groups B to E varied widely from 45 to $96 \%$ (Figure 2).

Mean values in groups B, C, and D ranged from 54 to $94 \%, 45$ to $86 \%$, and 45 to $96 \%$, respectively, and were significantly $(P<0.05)$ higher at d 0.2 as well as d 1 and 2 compared with $\mathrm{d}-3$ to $-1,0$, and 3 to 14 (Figure 2). Group E revealed mean DSCC values that only varied between 52 and $67 \%$ and did not indicate any significant differences.

Control quarters across all groups (A-E) revealed generally low DSCC values (mean: $45-62 \%$ ) and significant differences could not be found (Figure 2).

\section{Comparison of DSCC and SCC Changes Between Treatment Groups}

The effect of the different treatments (groups A-E) on DSCC and SCC, respectively, was analyzed for each time point (Tables 2 and 3 ).

$\boldsymbol{S C C}$. Mean $\log$ SCC values at d -3 to -1 and d 0 were in narrow ranges from 4.33 to 4.55 and 4.06 and 4.55 , respectively, and without significant differences between treatment groups (Table 2). At d 0.2, mean $\log$ SCC values varied broadly between 4.70 and 6.59 and were significantly $(P<0.05)$ higher in groups B to D compared with A. The treatment effect was further significantly $(P<0.05)$ higher in group B compared with group E. Mean values at $\mathrm{d} 1$ and 2 ranged from 4.37 to 5.87 and values in groups $\mathrm{B}$ to $\mathrm{D}$ were again significantly $(P<0.05)$ higher than in A. Further, the mean value in group B was significantly $(P<0.05)$ higher than in group E. Mean values at $\mathrm{d} 3$ to 14 ranged between 4.31 and 4.87 without any significant differences between treatment groups.

Table 3. Comparison of differential somatic cell count (DSCC) values (mean \pm SEM) measured in treated quarters between treatment groups $(\mathrm{A}-\mathrm{E})$

\begin{tabular}{|c|c|c|c|c|c|}
\hline & $\mathrm{A}$ & B & $\mathrm{C}$ & $\mathrm{D}$ & $\mathrm{E}$ \\
\hline Time $^{1}$ & Mean \pm SEM & Mean \pm SEM & Mean \pm SEM & Mean \pm SEM & Mean \pm SEM \\
\hline 2 & $59^{\mathrm{a}} \pm 6.16$ & $54^{\mathrm{a}} \pm 6.25$ & $49^{\mathrm{a}} \pm 6.99$ & $45^{\mathrm{a}} \pm 9.88$ & $52^{\mathrm{a}} \pm 6.99$ \\
\hline 3 & $60^{\mathrm{a}} \pm 7.71$ & $94^{\mathrm{b}} \pm 6.46$ & $86^{\mathrm{b}} \pm 7.23$ & $96^{\mathrm{b}} \pm 7.23$ & $67^{\mathrm{b}} \pm 7.23$ \\
\hline 4 & $55^{\mathrm{a}} \pm 6.16$ & $86^{\mathrm{b}} \pm 5.04$ & $81^{\mathrm{b}} \pm 6.50$ & $83^{\mathrm{b}} \pm 5.63$ & $64^{\mathrm{a}} \pm 5.63$ \\
\hline 5 & $54^{\mathrm{a}} \pm 6.16$ & $69^{\mathrm{a}} \pm 4.87$ & $63^{\mathrm{a}} \pm 5.44$ & $54^{\mathrm{a}} \pm 5.44$ & $59^{\mathrm{a}} \pm 5.44$ \\
\hline
\end{tabular}

${ }_{\mathrm{a}, \mathrm{b}}$ Different superscripts within a row indicate significant differences at $P<0.05$.

${ }^{1}$ Time: (1) baseline (i.e., d $-3,-2$, and -1 ); (2) right before treatment (i.e., d 0); (3) 5 h after treatment (i.e., d 0.2); (4) early cure phase (i.e., d 1 and 2); and (5) late cure phase (i.e., d 3, 4, 5, 6, 7, and 14). 
DSCC. Mean DSCC values observed at d -3 to -1 and d 0 ranged narrowly from 45 to $61 \%$ and 45 to $59 \%$, respectively, and did not differ between treatment groups (Table 3). Mean values in groups B to E $(67-96 \%)$ were significantly $(P<0.05)$ higher at $\mathrm{d}$ 0.2 compared with group A $(60 \%)$. Groups A and E indicated significantly $(P<0.05)$ lower mean values (55 and $64 \%$, respectively) at d 1 and 2 compared with groups B to D (81-86\%). At d 3 to 14, mean values lie in a range from 54 to $69 \%$ and did not differ significantly between treatment groups.

Effect of PRED. Comparing the LPS-treated cows with (group C) and without (group B) additional administration of PRED, mean log SCC values were lower in group B (d 0.2: 6.17 vs. 6.59, $\mathrm{d} 1$ and 2: 5.6 vs. 5.87 ) but the difference was not significant (Table 2). A similar observation was made for LTA-treated (group D) cows where the administration of PRED (group E) led to lower mean log SCC as well (d 0.2: 5.27 vs. 6.09; d 1 and 2: 4.81 vs. 5.25). In terms of DSCC, clearly lower proportions of DSCC were found when PRED was administered in LPS-treated cows (groups C vs. B: d 0.2: 86 vs. $94 \%$; d 1 and 2: 81 vs. $86 \%$ ). The effect of PRED was evident for LTA-treated cows (groups E vs. D: d 0.2: 67 vs. $96 \%$; 1 and 2: 64 vs. $83 \%$ ).

Example for Changes of DSCC and SCC in an Individual Cow. One cow from group D (i.e., LTA treatment) was selected to illustrate the changes of both DSCC and SCC during the course of the treatment experiment (Figure 3). The SCC was $<55,000$ cells $/ \mathrm{mL}$ in the treated quarter on $\mathrm{d}-3$ to 0 (Figure 3 ). The treatment (group D) resulted in a moderate increase to 168,000 cells $/ \mathrm{mL}$ on $\mathrm{d} 0.2$. On $\mathrm{d} 1$ to 2.5 , SCC were already down to a level of 80,000 cells $/ \mathrm{mL}$ and decreased further in the following days. The SCC in the control quarter varied between 17,000 and 80,000 cells $/ \mathrm{mL}$ and was highest on $\mathrm{d} 0.2$.

The DSCC was at a low level of $45 \%$ before treatment and increased to $90 \%$ in the treated quarter on $\mathrm{d} 0.2$ (Figure 3). Values remained at a high level (79-92\%) until d 3 and dropped to $45 \%$ on d 4 until the end of the experiment. The DSCC determined in the control quarter ranged from 45 to 70 with the highest value measured on d 1.5.

\section{Bacteriology}

In total, 240 microbiological examinations of cows in groups $\mathrm{A}$ to $\mathrm{E}$ were performed on $\mathrm{d}-2,1$, and 14 (all udder quarters tested). Whereas $90 \%$ of the tests showed no growth, contamination and CNS were found in 4.2 and $5.8 \%$ of quarters, respectively. All microbiological examinations were negative on $\mathrm{d}-2$. However, contamination and CNS were found in 4 and 2 quarters, respectively, on d 1. Furthermore, 6 and 12 quarters indicated contamination and CNS, respectively, on d 14 .

\section{Interrelation Between DSCC and SCC in Quarter Foremilk and Cow Composite Samples}

Quarter foremilk, quarter composite, and cow composite samples of 6 cows from samplings at $d-2$ and 5 relative to treatment were available to investigate the interrelation of the parameters DSCC and SCC in the different types of milk samples.

Quarter Foremilk and Quarter Composite Samples. Pearson correlation coefficients for the interrelation between DSCC and SCC each in quarter foremilk and quarter composite samples were calculated (Table 4). Significant $(P<0.05)$ correlations between SCC measured in quarter foremilk and quarter composite samples were found in the front right quarter at $\mathrm{d}$ $-2(\mathrm{r}=0.72)$ and in the rear right quarter at $\mathrm{d}-2(\mathrm{r}$ $=0.99)$ and $5(\mathrm{r}=0.99)$. In terms of DSCC, significant $(P<0.05)$ correlations for results measured in quarter foremilk and quarter composite samples were observed
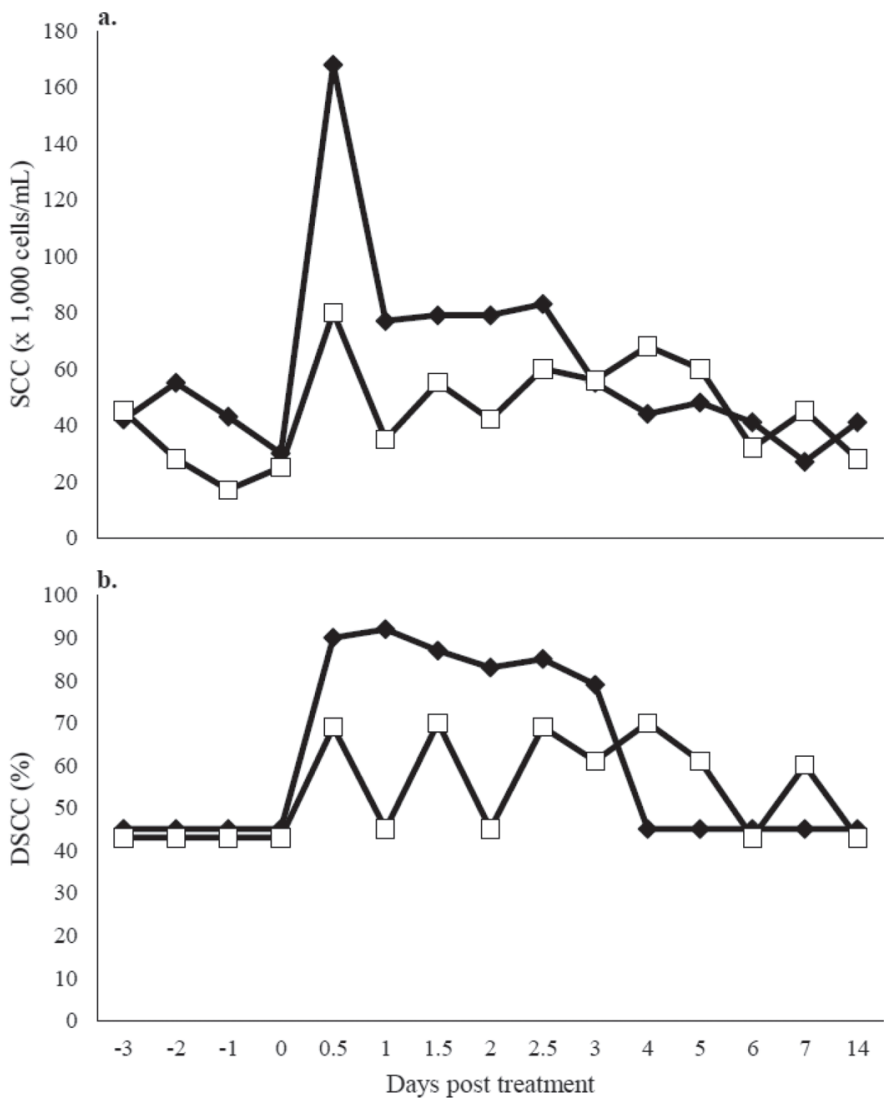

Figure 3. Example for the changes of SCC (a) and differential somatic cell count (DSCC, b) in treated $(\bullet)$ and control $(\square)$ quarters during the course of the experiment for 1 cow with lipoteichoic acid treatment (group D). 
Table 4. Pearson correlation coefficients and P-values for SCC and differential somatic cell count (DSCC), respectively measured in quarter foremilk and quarter composite samples

\begin{tabular}{|c|c|c|c|c|c|}
\hline \multirow[b]{2}{*}{ Quarter $^{1}$} & \multirow{2}{*}{$\begin{array}{l}\text { Day relative } \\
\text { to treatment }\end{array}$} & \multicolumn{2}{|c|}{$\mathrm{SCC}$} & \multicolumn{2}{|c|}{ DSCC } \\
\hline & & $\mathrm{r}$ & $P$-value & $\mathrm{r}$ & $P$-value \\
\hline \multirow[t]{2}{*}{ FR } & -2 & 0.72 & $*$ & 0.71 & $*$ \\
\hline & 5 & 0.31 & NS & 0.66 & NS \\
\hline \multirow[t]{2}{*}{$\mathrm{RR}$} & -2 & 0.99 & $* * *$ & 0.92 & $* * *$ \\
\hline & 5 & 0.99 & $* * *$ & 0.89 & $* *$ \\
\hline \multirow[t]{2}{*}{$\mathrm{FL}$} & -2 & 0.36 & NS & 0.81 & $*$ \\
\hline & 5 & 0.51 & NS & 0.51 & NS \\
\hline \multirow[t]{2}{*}{ RL } & -2 & 0.47 & NS & 0.60 & NS \\
\hline & 5 & 0.31 & NS & 0.70 & NS \\
\hline
\end{tabular}

${ }^{1} \mathrm{FR}=$ front right; $\mathrm{RR}=$ rear right; $\mathrm{FL}=$ front left; and $\mathrm{RL}=$ rear left.

*** $P<0.001 ;{ }^{*} P<0.01 ;{ }^{*} P<0.05 ; \mathrm{NS}=P>0.05$.

in the front right quarter at $\mathrm{d}-2(\mathrm{r}=0.71)$, the rear right quarter at $\mathrm{d}-2(\mathrm{r}=0.92)$ and $5(\mathrm{r}=0.89)$, and the front left quarter at $\mathrm{d}-2(\mathrm{r}=0.81)$.

Quarter Composite and Cow Composite Samples. Pearson correlation coefficients to describe the interrelation between DSCC and SCC in the quarter composite and cow composite samples were calculated (Table 5). The SCC values determined in the quarter composite correlated significantly $(P<0.001)$ with those in cow composite samples at both $\mathrm{d}-2$ and 5 (r $=0.91$ and $\mathrm{r}=0.99$, respectively). The correlation was slightly less significant $(P<0.05)$ for the DSCC parameter $(\mathrm{r}=0.70$ and $\mathrm{r}=0.89$ at $\mathrm{d}-2$ and 5 , respectively).

\section{DISCUSSION}

Somatic cell count is the key parameter in routine mastitis monitoring programs (e.g., in the frame of dairy herd improvement testing) around the globe today. Nevertheless, mastitis is still causing tremendous economic losses to the dairy industry (Halasa et al., 2007). Recently, the DSCC parameter was developed, allowing differentiation of milk immune cells into 2 groups, PMN and lymphocytes versus macrophages, at a high speed and low cost in a reliable and repeatable way based on flow cytometry technology. This value is complementary to SCC, providing more information on the actual immune response of the mammary gland (Damm et al., 2017). Nothing is yet described regard-

Table 5. Pearson correlation coefficients and $P$-values for SCC and differential somatic cell count (DSCC), respectively measured in quarter composite and cow composite samples

\begin{tabular}{lccrccc}
\hline & \multicolumn{2}{c}{$\mathrm{SCC}$} & & \multicolumn{2}{c}{$\mathrm{DSCC}$} \\
\cline { 2 - 3 } \cline { 5 - 6 } $\begin{array}{l}\text { Day relative } \\
\text { to treatment }\end{array}$ & $\mathrm{r}$ & $P$-value & & $\mathrm{r}$ & $P$-value \\
\hline-2 & 0.91 & $* *$ & & 0.70 & $*$ \\
5 & 0.99 & $* * *$ & & 0.89 & $* *$ \\
\hline$* * * P<0.001 ; * * P<0.01 ; * P<0.05$. & & &
\end{tabular}

ing the behavior of the new DSCC parameter during the course of mastitis. Hence, the primary aim of this study was to investigate the changes of both DSCC and SCC before, during, and after mastitis induced by either LPS from Escherichia coli or LTA from Staphylococcus aureus. Thus, the study provides basic insights on the new DSCC parameter and potential practical applications in the frame of dairy herd improvement testing programs.

We specifically used bacterial cell wall components, namely LPS and LTA, to induce a defined inflammatory response (Wellnitz et al., 2013). In fact, with LPS as a cell wall component from E. coli and LTA as a cell wall component from $S$. aureus, we chose bacterial cell wall components representing 2 very common mastitiscausing pathogens (Sampimon et al., 2009; Schwarz et al., 2010). Furthermore, E. coli and S. aureus typically induce mastitis of different severities. Escherichia coli is a gram-negative bacterium that is typically associated with acute, clinical mastitis, whereas $S$. aureus, a grampositive bacterium, is typically associated with subclinical mastitis. However, in our study only the bacterial cell wall components LPS or LTA of the bacteria were administered. Hence, our model stimulated the immune response very well but has limitations representing real infection because bacteria would start growing once they invaded the mammary gland in naturally occurring infections.

The SCC increased significantly in response to LPS and LTA stimulation (Figure 2), which was to be expected given that part of the initial immune response is the recruitment of substantial numbers of immune cells from the blood stream (Sordillo et al., 1997). Similar significant SCC increases in response to controlled LTA- or LPS-induced mastitis were described previously (Shuster and Kehrli, 1995; Giovannini et al., 2017).

The second parameter investigated, DSCC, represents the percentage of PMN combined with lympho- 
cytes and is described in detail elsewhere (Damm et al., 2017). Briefly, during method development microscopic analyses of cow composite samples revealed that percentages of PMN increased whereas those of macrophages decreased as SCC increased. Lymphocytes, however, occurred with fairly low proportions (0-19\%) across the entire analyzed SCC range. Nevertheless, DSCC reflects results from previously published work reporting about dominant proportions of macrophages in the milk of healthy cows (e.g., Lee et al., 1980) and predominantly neutrophils in the milk of cows with mastitis (e.g., Paape et al., 1979; Kehrli and Shuster, 1994). Proportions of macrophages can be calculated by $100-$ DSCC.

The DSCC indicated significant changes in response to LPS and LTA stimulation (Figure 2). Whereas low DSCC values, indicating low proportions of PMN and lymphocytes and thus high proportions of macrophages, were observed before the challenge, higher DSCC values were seen after the stimulus. This clearly indicates that the composition of the immune cells changed to predominantly PMN after stimulation. A significant increase of proportions of PMN after infection has been described previously (Paape et al., 1979; Kehrli and Shuster, 1994; Shuster and Kehrli, 1995; Sordillo et al., 1997). Nevertheless, this is the first study describing the change of the DSCC parameter during mastitis. Even though DSCC represents the proportion of both PMN and lymphocytes, it should be noted that PMN are the predominant population whereas lymphocytes play a minor role as discussed above and extensively elsewhere (Damm et al., 2017). Similar to SCC, the significant increase in DSCC lasted for $2 \mathrm{~d}$ postchallenge with LPS, however, DSCC remained at significantly elevated levels in the LTA group as well.

Comparing the changes of DSCC and SCC during the course of our study, similar patterns could be observed. Values for both parameters were at low levels before stimulation, increased significantly after stimulation, and decreased similarly afterward. Nevertheless, in animals with moderate SCC increases after stimulation (e.g., Figure 3), an evident shift in the composition of the cells (DSCC) occurred. This indicates that the immune response in the form of predominant PMN proportions can occur even at low SCC levels and thus serves as a first indication of mastitis. Dominating PMN proportions in quarter foremilk milk samples with as low as 9,000 cells $/ \mathrm{mL}$ were described previously (Schwarz et al., 2011a,b; Pilla et al., 2012) and interpreted as the onset/early signs of mastitis. In this context, elevated DSCC results could be used as an early indicator for mastitis. However, the number of cells available for determination of DSCC depends on the SCC, and in this context, to obtain sufficient statistics (e.g., repeatability) for DSCC, a minimum SCC of $\geq 50,000$ cells $/ \mathrm{mL}$ is required as described in detail elsewhere (Damm et al., 2017). Nevertheless, the frequency of infections in the SCC range $<50,000$ cells / $\mathrm{mL}$ was demonstrated to be low ( $<4 \%$ culture-positive results) and first increased at a higher SCC (Schwarz et al., 2010). This, in turn, indicates that the focus of improving the detection of subclinical mastitis should be in the range of $>50,000$ cells $/ \mathrm{mL}$.

As a result of the 50,000 cells $/ \mathrm{mL}$ limitation (Damm et al., 2017), all DSCC values determined in samples with $<50,000$ cells $/ \mathrm{mL}$ were set to $45 \%$ in our study, which in turn indicates a predominance of macrophages. Predominating proportions of macrophages in healthy mammary glands were described in various other studies (e.g., Lee et al., 1980; Sordillo, 1997; Sarikaya et al., 2005). However, due to this technical limitation we could not precisely describe the pattern of DSCC in samples with $<50,000$ cells $/ \mathrm{mL}$.

In terms of a DSCC threshold for differentiation between uninfected and infected quarters, our study indicated DSCC values $>86 \%$ during the first $2 \mathrm{~d}$ after stimulation with either LPS or LTA and without PRED treatment each (groups B and D). Therefore, DSCC of $86 \%$ might be used as a first indication for a threshold. However, a large data set with information on the bacteriological status as well as SCC and DSCC would be required for a thorough determination of a DSCC threshold and the respective sensitivity and specificity.

Microbiological testing of quarter foremilk samples was performed once before and twice after stimulation/challenge with LPS and LTA to ensure absence of IMI. Only culture-negative and low SCC cows as well as quarters were included in the trial. Of all quarters tested at the 3 different time points, all results were negative before the challenge. However, after the challenge, 4 quarters revealed contamination and 2 revealed CNS. The test on d 14 indicated contamination in 6 quarters and CNS in 12 quarters. Coagulase-negative staphylococci are known to occur naturally in the teat canal without causing IMI (Vanderhaeghen et al., 2014). Hence, we excluded that the detected microorganisms affected SCC or DSCC results in our study.

The anti-inflammatory glucocorticoid PRED is increasingly added to intramammary antibiotic injectors in Europe to aid in reducing inflammation associated with mastitis and several studies have recently investigated the effects of PRED in the mammary gland (Sipka et al., 2013, Wellnitz et al., 2014; Wall et al., 2016). In the present study, PRED treatment only had significant effects on quarters treated with LTA (group E). These results showed that although there was a significant increase in SCC between the pretreatment and posttreatment time points, this increase was still 
minimal and SCC in these quarters was not different from the control quarters (group A) at the d 0.2 time point. This could be due the fact that PRED has been shown to induce the formation of tight junctions (junctional complexes between mammary epithelial cells) in mouse mammary cells (Zettl et al., 1992), which could increase the integrity of the blood-milk barrier. These results are also in accordance with Wall et al. (2016) that showed the administration of PRED also had an effect on only quarters treated with LTA. Furthermore, when comparing between quarters that received LTA (group D) with quarters that received LTA and PRED (group E), there was higher mean SCC and a higher DSCC value in quarters not treated with PRED, further confirming the effect of PRED on the mammary immune system.

The administration of PRED in quarters treated with LPS (group C) did not have an effect on cell migration as these quarters had a higher SCC and a shift in DSCC value compared with the control quarters (group A), indicating migrating PMN. These quarters also had a higher SCC and DSCC between the pretreatment and posttreatment time points. Although there was a reduction in the SCC and DSCC value when comparing LPS quarters that received PRED (group C) with those that did not (group B), these results were not significant. These results are in agreement with Wellnitz et al. (2014) who also did not see a PRED effect on cell migration in quarters challenged with LPS.

There could be several reasons that PRED did not have an effect on cell migration in LPS quarters. It has been previously shown that PRED can bind to the glucocorticoid receptor on cells, blocking the production of pro-inflammatory cytokines (Stahn et al., 2007) and importantly, PRED can also affect the recruitment of cells to sites of inflammation due to this modification in cytokine and chemokine production (Schwiebert et al., 1996). However, LPS is such a strong immune stimulus in the mammary gland, that it can be speculated that this dose of $30 \mathrm{mg}$ PRED could not attenuate the immune response. Furthermore, PRED is known to increase the integrity of the blood-milk barrier (Wellnitz et al., 2014); however, this increased integrity of the barrier did not have an effect on cell migration in the LPS treated quarters. Due to these points, we hypothesize that these results could be due to LPS causing additional mammary epithelial cell degradation and damage to the mammary gland (Wellnitz et al., 2016) or PMN could also be following a transcellular instead of paracellular route of entry into the mammary gland. This route of migration has been hypothesized for PMN migrating through the endothelium to the site of sterile inflammation (McDonald and Kubes, 2011).
The differential PRED effect in LPS- and LTA-treated quarters could also be due to differing cytokine expression profiles between LPS and LTA, which has been shown previously in vitro (Griesbeck-Zilch et al., 2008). Furthermore, previous evidence has shown that during E. coli mastitis, IL-8 expression is upregulated in both epithelial and endothelial cells in the mammary gland, especially around the alveoli (McClenahan et al., 2006). This IL-8 upregulation aids in the migration of neutrophils into the mammary gland. These results could also explain why cell migration in the LPS-treated quarters is not affected by PRED.

Our study was part of a larger project (Wall et al., 2016) in which additional blood-milk barrier parameters were studied. As such, the concentrations of LPS and LTA were calibrated to induce a similar SCC increase. This allowed for the standardization of the immune system and a quantitative comparison of additional factors (Bruckmaier and Wellnitz, 2017). However, biopsies were performed to measure the expression of proinflammatory cytokines in the mammary tissue in response to LPS and LTA. As for our study, only milk samples from quarters not being biopsied were included. Consequently, physically collected cow composite samples could not be included in our data analysis because milk from biopsied udder quarters contained blood in some cases. Nevertheless, we investigated the relationship between quarter foremilk, quarter composite, and cow composite samples based on 6 randomly selected animals at 2 time points during the trial (i.e., $\mathrm{d}-2$ and 5 , meaning: $\mathrm{d}-2$ : before biopsy was done and $\mathrm{d} 5$ : after completion of healing from the biopsy).

Pearson correlation coefficients, typically used for describing the statistical association between 2 variables (both magnitude and direction of the association), were determined for DSCC and SCC each determined in quarter foremilk, quarter composite, and cow composite samples. Both DSCC and SCC values measured in quarter foremilk and quarter composite samples indicated significant correlations for some quarters, particularly those with slightly elevated SCC (e.g., rear right quarters where mastitis was induced). Our observations were in accordance with previously published results (Wellnitz et al., 2009) indicating that quarter composite SCC could be reliably predicted based on the use of SCC from quarter foremilk samples. However, although such prediction worked very well in the SCC range 50,000 to 300,000 cells/mL, SCC in quarter composite samples were typically underestimated when quarter foremilk samples showed SCC $<50,000$ cells/ $\mathrm{mL}$.

We further found clear correlations between both DSCC and SCC values measured in quarter composite 
and cow composite samples. This observation might be explainable by the relatively equal SCC levels of the individual quarters, although our data indicated that a single quarter with elevated SCC (i.e., the quarter where mastitis was induced) was reflected in the cow composite sample in terms of both DSCC and SCC. A previous study (Berglund et al., 2007) has also observed this effect for SCC.

It is well known that high SCC milk from an infected mammary quarter of a cow is diluted with normal low SCC milk from uninfected quarters in cow composite samples (i.e., dilution effect), thus reducing sensitivity in mastitis monitoring programs (Reyher and Dohoo, 2011). Hence, this is clearly a challenge to the dairy industry. The results from our investigation of the interrelation of DSCC and SCC in different types of milk samples support that when employing the combination of DSCC and SCC in cow composite samples, not only the SCC increase but also the shift in cell populations or rather increase in DSCC would be reflected. As a result, in low SCC samples in particular the presence of many PMN (i.e., high \% DSCC) could be used as an indicator for mastitis in at least one quarter. An infected quarter contributes not only elevated numbers of cells to SCC in cow composite samples, but at the same time these cells predominantly consist of PMN (e.g., DSCC > 85\%) compared with normal quarters with low SCC and mostly low DSCC. Consequently, an individual quarter would be more clearly reflected in cow composite samples when working with both DSCC and SCC compared with working with SCC alone. Therefore, utilizing DSCC and SCC information could lead to increased sensitivities in mastitis monitoring programs based on cow composite samples.

\section{CONCLUSIONS}

This is the first ever study investigating the new DSCC parameter during induced mastitis using cell wall components from 2 frequently occurring mastitiscausing pathogens, S. aureus and E. coli, under controlled conditions. As a result, DSCC values increased significantly when comparing results before and after the stimulation of the immune response using the bacterial cell wall components LPS and LTA. This, in turn, reflects the shift of cell populations in milk from predominantly macrophages to predominantly PMN. The SCC increased markedly after stimulation, as expected. Interestingly though, we observed the shift in DSCC even when SCC increased moderately only in individual animals. Hence, elevated DSCC values in low SCC samples could be applied as an indicator for the onset of mastitis in practice. Our results further indicate that both DSCC and SCC measured in samples from individual quarters were reflected in cow composite samples. Specifically, not only the SCC increase but also the shift in cell populations to predominantly PMN from an individual infected quarter can be detected measuring DSCC and SCC in cow composite samples. In this context, the additional DSCC parameter could be used for improving sensitivity in detecting mastitis in the frame of mastitis monitoring programs based on cow composite samples. Our study indicated that the DSCC threshold for differentiation of uninfected and infected quarters might be $86 \%$, but a more appropriate and thorough investigation of an ideal threshold and the respective sensitivity and specificity are required. In terms of further practical applications of DSCC for the dairy industry, the combination of DSCC and SCC could be employed to actually define the stage of mastitis. Specifically, high SCC values ( $>200,000$ cells / $\mathrm{mL})$ in combination with high DSCC values $(>86 \%)$ indicated the early stage of mastitis (e.g., active immune response by elevated numbers and proportions of PMN) in our study. On the contrary, high SCC values in combination with low DSCC values $(<86 \%)$ rather indicated the late stage of mastitis (i.e., cure phase). However, further research is needed to validate the suggested practical applications of the new DSCC parameter in the frame of dairy herd improvement programs based on large-scale longitudinal studies.

\section{ACKNOWLEDGMENTS}

This study was supported by the Swiss National Science Foundation (Bern, Switzerland; grant no. 149460). The authors further thank Mille Bundgaard, Malin Damm, and Jurgita Sørensen (FOSS Analytical A/S, Hilleroed, Denmark) for their excellent technical assistance.

\section{REFERENCES}

Berglund, I., G. Pettersson, K. Östensson, and K. SvennerstenSjaunja. 2007. Quarter milking for improved detection of increased SCC. Reprod. Domest. Anim. 42:427-432.

Bruckmaier, R. M., and O. Wellnitz. 2017. Triennial Lactation Symposium/BOLFA: Pathogen-specific immune response and changes in the blood-milk barrier of the bovine mammary gland. J. Anim. Sci. 95:5720-5728.

Damm, M., C. Holm, M. Blaabjerg, M. Bro Nielsen, and D. Schwarz. 2017. Differential somatic cell count-A novel method for routine mastitis screening in the frame of Dairy Herd Improvement testing programs. J. Dairy Sci. 100:4926-4940.

Giovannini, A. E. J., B. H. P. van den Borne, S. K. Wall, O. Wellnitz, R. M. Bruckmaier, and C. Spadavecchia. 2017. Experimentally induced subclinical mastitis: Are lipopolysaccharide and lipoteichoic acid eliciting similar pain responses? Acta Vet. Scand. 59:40-53.

Griesbeck-Zilch, B., H. H. D. Meyer, C. Kühn, M. Schwerin, and O. Wellnitz. 2008. Staphylococcus aureus and Escherichia coli cause deviating expression profiles of cytokines and lactoferrin messenger ribonucleic acid in mammary epithelial cells. J. Dairy Sci. $91: 2215-2224$ 
Halasa, T., K. Huijps, O. Osteras, and H. Hogeveen. 2007. Economic effects of bovine mastitis and mastitis management: A review. Vet. Q. 29:18-31.

IDF (International Dairy Federation). 2013. Guidelines for the use and interpretation of bovine milk somatic cell count. Bull. IDF. $466 / 2013$.

Kehrli, M. E., and D. E. Shuster. 1994. Factors affecting milk somatic cells and their role in health of the bovine mammary gland. J. Dairy Sci. 77:619-627.

Lee, C. S., F. B. P. Wooding, and P. Kemp. 1980. Identification properties and differential counts of cell populations using electron microscopy of dry cow secretions, colostrum and milk from normal cows. J. Dairy Res. 47:39-50.

McClenahan, D., R. Krueger, H. Y. Lee, C. Thomas, M. E. Kehrli Jr., and C. Czuprynski. 2006. Interleukin-8 expression by mammary gland endothelial and epithelial cells following experimental mastitis infection with E. coli. Comp. Immunol. Microbiol. Infect. Dis. 29:127-137.

McDonald, B., and P. Kubes. 2011. Cellular and molecular choreography of neutrophil recruitment to sites of sterile inflammation. J. Mol. Med. (Berl.) 89:1079-1088.

NMC. 2004. Microbiological Procedures for the Diagnosis of Bovine Udder Infection and Determination of Milk Quality. National Mastitis Council (NMC), Verona, WI

Paape, M. J., W. P. Wergin, A. J. Guidry, and R. E. Pearson. 1979 Leukocytes-Second line of defense against invading mastitis pathogens. J. Dairy Sci. 62:135-153.

Pilla, R., M. Malvisi, G. Snel, D. Schwarz, S. König, C.-P. Czerny, and R. Piccinini. 2013. Differential cell count as an alternative method to diagnose dairy cow mastitis. J. Dairy Sci. 96:1653-1660.

Pilla, R., D. Schwarz, S. Konig, and R. Piccinini. 2012. Microscopic differential cell counting to identify inflammatory reactions in dairy cow quarter milk samples. J. Dairy Sci. 95:4410-4420.

Reyher, K. K., and I. R. Dohoo. 2011. Diagnosing intramammary infections: Evaluation of composite milk samples to detect intramammary infections. J. Dairy Sci. 94:3387-3396.

Roth, J. A., and M. L. Kaeberle. 1981. Effects of in vivo dexamethasone administration on in vitro bovine polymorphonuclear leukocyte function. Infect. Immun. 33:434-441.

Roth, J. A., and M. L. Kaeberle. 1982. Effect of glucocorticoids on the bovine immune system. J. Am. Vet. Med. Assoc. 180:894-901.

Sampimon, O., H. W. Barkema, I. Berends, J. Sol, and T. Lam. 2009 Prevalence of intramammary infection in Dutch dairy herds. J. Dairy Res. 76:129-136.

Sandholm, M. 1976. Coagulation of serum by glutaraldehyde. Clin. Biochem. 9:39-41.

Sarikaya, H., C. Werner-Misof, M. Atzkern, and R. M. Bruckmaier. 2005. Distribution of leucocyte populations, and milk composition, in milk fractions of healthy quarters in dairy cows. J. Dairy Res. $72: 486-492$.

Schwarz, D., U. S. Diesterbeck, K. Failing, S. Konig, K. Brugemann, M. Zschock, W. Wolter, and C.-P. Czerny. 2010. Somatic cell counts and bacteriological status in quarter foremilk samples of cows in Hesse, Germany-A longitudinal study. J. Dairy Sci. 93:5716-5728.

Schwarz, D., U. S. Diesterbeck, S. Konig, K. Brugemann, K. Schlez, M. Zschock, W. Wolter, and C.-P. Czerny. 2011a. Flow cytometric differential cell counts in milk for the evaluation of inflammatory reactions in clinically healthy and subclinically infected bovine mammary glands. J. Dairy Sci. 94:5033-5044.
Schwarz, D., U. S. Diesterbeck, S. König, K. Brügemann, K. Schlez, M. Zschöck, W. Wolter, and C.-P. Czerny. 2011b. Microscopic differential cell counts in milk for the evaluation of inflammatory reactions in clinically healthy and subclinically infected bovine mammary glands. J. Dairy Res. 78:448-455.

Schwiebert, L. M., L. A. Beck, and C. Stellato. 1996. Glucocorticosteroid inhibition of cytokine production and relevance to antiallergic actions. J. Allergy Clin. Immunol. 97:143-152.

Shuster, D. E., and M. E. Kehrli. 1995. Administration of recombinant human interleukin 1 receptor antagonist during endotoxin-induced mastitis in cows. Am. J. Vet. Res. 56:313-320.

Sipka, A., A. Gurjar, S. Klaessig, G. E. Duhamel, A. Skidmore, J. Swinkels, P. Cox, and Y. Schukken. 2013. Prednisolone and cefapirin act synergistically in resolving experimental Escherichia coli mastitis. J. Dairy Sci. 96:4406-4418.

Sordillo, L. M., and S. C. Nickerson. 1988. Morphometric changes in the bovine mammary gland during involution and lactogenesis. Am. J. Vet. Res. 49:1112-1120.

Sordillo, L. M., K. Shafer-Weaver, and D. DeRosa. 1997. Immunobiology of the mammary gland. J. Dairy Sci. 80:1851-1865.

Stahn, C., M. Löwenburg, D. W. Hommes, and F. Buttgereit. 2007. Molecular mechanisms of glucocorticoid action and selective glucocorticoid receptor agonists. Mol. Cell. Endocrinol. 275:71-78.

Tøllbøll, T., and R. J. Jørgensen. 2003. The glutaraldehyde coagulation test (GCT) used to predict health status in dairy herds. Acta Vet. Scand. 44:113

Vanderhaeghen, W.. S. Piepers, F. Leroy, E. Van Coillie, F. Haesebrouck, and S. De Vliegher. 2014. Invited review: Effect, persistence, and virulence of coagulase-negative Staphylococcus species associated with ruminant udder health. J. Dairy Sci. 97:5275-5293.

Wall, S. K., L. E. Hernandez-Castellano, A. Ahmadpour, R. M. Bruckmaier, and O. Wellnitz. 2016. Differential glucocorticoid-induced closure of the blow-milk barrier during lipopolysaccharide- and lipoteichoic acid-induced mastitis in dairy cows. J. Dairy Sci. 99:7544-7553.

Wellnitz, O., E. T. Arnold, M. Lehmann, and R. M. Bruckmaier. 2013. Short communication: Differential immunoglobulin transfer during mastitis challenge by pathogen-specific components. J. Dairy Sci. 96:1681-1684.

Wellnitz, O., M. G. Doherr, M. Woloszyn, and R. M. Bruckmaier. 2009. Prediction of total quarter milk somatic cell counts based on foremilk sampling. J. Dairy Res. 76:326-330.

Wellnitz, O., S. K. Wall, M. Saudenova, and R. M. Bruckmaier. 2014 Effect of intramammary administration of prednisolone on the blood-milk barrier during the immune response of the mammary gland to lipopolysaccharide. Am. J. Vet. Res. 75:595-601.

Wellnitz, O., C. Zbinden, X. Huang, and R. M. Bruckmaier. 2016. Short communication: Differential loss of bovine mammary epithelial barrier integrity in response to lipopolysaccharide and lipoteichoic acid. J. Dairy Sci. 99:4851-4856.

Zarrin, M., O. Wellnitz, H. A. van Dorland, J. J. Gross, and R. M. Bruckmaier. 2014. Hyperketonemia during lipopolysaccharide-induced mastitis affects systemic and local intramammary metabolism in dairy cows. J. Dairy Sci. 97:3531-3541.

Zettl, K. S., M. D. Sjaastad, P. M. Riskin, G. Parry, T. E. Machen, and G. L. Firestone. 1992. Glucocorticoid-induced formation of tight junctions in mouse mammary epithelial cells in vitro. Proc. Natl. Acad. Sci. USA 89:9069-9073. 